\title{
Synthesis and NMR Spectroscopic Characterization of Organometallics in the Laboratory of Wolfgang von Philipsborn: Reminiscences of Former Graduate Students
}

\author{
Andreas Hafner ${ }^{\mathrm{a}}$, Daniel Nanz ${ }^{\mathrm{b}}$, Umberto Piantinic ${ }^{\mathrm{c}}$, Daniel Rentsch ${ }^{\mathrm{d}}$, Carlo Täschlere, and \\ Oliver Zerbe*f
}

Dedicated to Prof. Wolfgang von Philipsborn on the occasion of his $80^{\text {th }}$ birthday

\begin{abstract}
On the occasion of his $80^{\text {th }}$ birthday, former graduate students from the group of Prof. Wolfgang von Philipsborn from the Institute of Organic Chemistry, University of Zurich, describe from a personal perspective the scientific achievements of his group in the field of nuclear magnetic resonance, mainly applied to transition metals and in the field of organometallic chemistry. Interest in metal chemical shifts is driven by the need to understand reactivity of organometallic compounds in catalysis. Progress in the field is very much related to the technical development of NMR instruments. The range of experiments spans from simple 1D experiments with direct metal detection to 2D NMR experiments, in which metal frequencies are encoded via their attached protons or phosphorous ligands. Other examples come from the structural biology of metal-containing proteins or form the measurement of scalar couplings to quadrupolar nuclei via lineshape analysis. A particular emphasis is presented on how collaborations from various groups at the campus have been fruitful to the scientific progress in the von Philipsborn group. The article also contains a number of personal anecdotes that document life of the graduate students in his group at that time.
\end{abstract}

Keywords: NMR · von Philipsborn, W.

\author{
${ }^{\star}$ Correspondence: Prof. Dr. O. Zerbe ${ }^{f}$ \\ Tel.: +41446354263 \\ E-mail: oliver.zerbe@oci.uzh.ch \\ aBASF \\ K-420.2.20, P.O. Box \\ $\mathrm{CH}-4002$ Basel \\ bUniversitätsspital Zürich \\ Departement Medizinische Radiologie \\ MR-Zentrum, Rämistrasse 100 \\ $\mathrm{CH}-8091$ Zürich \\ 'University of Applied Sciences \\ Western Switzerland \\ Route du Rawyl 64 \\ $\mathrm{CH}-1950$ Sion \\ 'Swiss Federal Laboratories for Material Testing and \\ Research (Empa) \\ Überlandstrasse 129 \\ $\mathrm{CH}-8600$ Dübendorf \\ eKantonsschule Limmattal \\ In der Luberzen 34 \\ $\mathrm{CH}-8902$ Urdorf \\ IInstitute of Organic Chemistry \\ University of Zurich \\ Winterthurerstrasse 190 \\ $\mathrm{CH}-8057$ Zurich
}

Having worked more than one or two decades in academia or industry we like to think back to the days in the laboratory of our former mentor Wolfgang von Philipsborn.

\section{Biography}

Wolfgang von Philipsborn was born on the $25^{\text {th }}$ of September, 1929, in Germany. He studied chemistry from 1949 to 1952 at the Free University, Berlin. He then moved to the University of Zurich, where he received his $\mathrm{PhD}$ in 1956 under the guidance of H. Schmid with a thesis entitled 'Zur Konstitution des C-Cumarins und über Reaktionen von Verbindungen mit Indolein-Struktur'. Thereafter he spent a postdoctoral period at the Massachusetts Institute of Technology in the group of $\mathbf{J}$. C. Sheehan. At that time the main focus of his work was on natural product chemistry. However, already in those days, he became interested in NMR, and applied double-resonance techniques to indirectly detect ${ }^{15} \mathrm{~N}$ resonances. He returned to $\mathrm{Zu}$ rich in 1961, and received the university's Venia Legendi at the Institute of Organic
Chemistry in 1963 ('ProtonenresonanzSpektroskopie organischer Verbindungen'). He soon was promoted to Assistant (1966), Associate (1969) and Full Professor (1974), in which function he served until his retirement in 1997. In between he held more than 20 visiting professorships at several Universities and Research Institutes. During his academic career he was honored with the Alfred-Werner-Medal in 1965 and with the Centennial Medal of the Case Institute of Technology (Cleveland) in 1980 . He was a Swiss delegate to the IUPAC from 1985 onwards and President of the Swiss Chemical Society from 1990 to 1992, and later became an Honorary Member. He was the editor of 'Magnetic Resonance in Chemistry' (formerly 'Organic Magnetic Resonance'), a leading journal for NMR spectroscopy applied to problems in chemistry and biology.

\section{Main Research Interests}

Among the reasons for us to join Prof. von Philipsborn's research team was the multidisciplinarity in his approach to research. Not only was he known for expert 
structure elucidation of complex organic compounds, but he was also famous for cutting-edge development and application of NMR techniques for the characterization of structural properties of organometallic compounds and of mechanistic aspects of their role as catalysts. Despite this focus on NMR, the capability to synthesize as yet non-existent compounds also continuously exerted a strong fascination on Prof. von Philipsborn. His synthetic work was mainly concerned with organometallic chemistry $\left(e . g .{ }^{[1]}\right)$, often in collaboration with his colleagues in inorganic chemistry at the University, e.g. Albrecht Salzer or Heinz Berke, or from the ETH, e.g. Luigi Venanzi and Paul Pregosin, but also from shared projects with the groups of Bönnemann at the Max Plank Institute in Mühlheim ${ }^{[2]}$ and the DeShong group ${ }^{[3-5]}$ in the US. His spectroscopic work started out with the analysis of natural products, and concerned many aspects of ${ }^{15} \mathrm{~N}$ NMR. $\left.{ }^{6}\right]$ Later on, he became famous for his research in transition metal NMR, ${ }^{[7]}$ a field that he remained active in for the rest of his career. Detection of insensitive transition-metal nuclei by NMR was first made possible with the advent of broadband spectrometers equipped with large-volume probe heads. The first instrument of this kind in Switzerland was installed in the von Philipsborn group, allowing the direct detection of insensitive low-frequency spin-1/2 nuclei, such as ${ }^{57} \mathrm{Fe},{ }^{103} \mathrm{Rh}$, or ${ }^{183} \mathrm{~W}$, as well as of quadrupolar nuclei, e.g. ${ }^{59} \mathrm{Co}$ or ${ }^{55} \mathrm{Mn}$. As a result, the study of the structural dependence of metal-NMR parameters, i.e. chemical shifts, heteronuclear and homonuclear spin-spin coupling and quadrupolar coupling constants and relaxation times, became a fruitful field of research. ${ }^{[8-10]}$ A particular highlight that combined both his interests in organometallic chemistry as well as in transition metal NMR was the establishment of a relationship between ${ }^{59} \mathrm{Co}$ chemical shifts of catalysts and the rate of substrate conversion, ${ }^{[2]}$ and similar relationships were also described for other systems. ${ }^{[9,11,12]}$ Apart from applied spectroscopy there was also always an interest in methods development, e.g. in the field of double-resonance or indirect detection ${ }^{[13]}$ (vide infra). Interestingly, von Philipsborn investigated the dependence of one-bond $\mathrm{C} \alpha-\mathrm{H} \alpha$ coupling constants in peptides long before this topic was picked up again by the biomolecular NMR community. ${ }^{[14]}$

\section{Philosophy of Leadership}

Prof. von Philipsborn realized very early on that borders between institutes and institutions hamper progress in science. $\mathrm{He}$ always strongly supported interdisciplinary collaborations; and it was common to find guest researchers from all over the world in his laboratory. All of us had worked in different areas of chemistry before joining the von Philipsborn laboratory: e.g. in synthesis at the Institute of Inorganic Chemistry of the University of Zurich, in spectroscopy at the Institute of Physical Chemistry or in organic chemistry at the Laboratory of Organic Chemistry at the Swiss-Federal Institute of Technology $(\mathrm{ETH})$, or in organometallic catalysis at the Institute of Inorganic Chemistry at the University of Hamburg. Von Philipsborn strongly encouraged us to further develop and maintain good relationships with a diverse range of other research groups as well as with industry during the time we spent in his group. His generosity strongly influenced not only the evolution of these collaborations but also the development of our own personalities. We like to describe von Philipsborn as a true gentleman. Another important success factor for our own careers was the fact that 'Phibo', as we used to call him, gave us lavish time to learn to swim in new areas of science and, by doing so, become more and more independent. When in danger of drowning, we were always additionally supported by project partners (e.g. by Prof. Albrecht Salzer from the Institute of Inorganic Chemistry, Heinz Rüegger or Luigi Venanzi from the Laboratory of Inorganic Chemistry, ETHZ or his colleagues John Robinson (Institute of Organic Chemistry) or Milan Vašák (Department of Biochemistry). Finally, group life was heavily influenced by the good soul of the group, von Philipsborn's secretary Erika Gysi-Wolf, whose competence, reliability and integrity and constant good humor was deeply appreciated by everybody in the group. Finally, a number of talented technicians supported the NMR team, during the last two decades those were Markus Vöhler, Thomas Plüss, Martin Binder, Nadja Bross and Simon Jurt.

\section{Cutting-edge Instrumentation...}

Wolfgang von Philipsborn made his first steps into NMR spectroscopy at times which are generally considered to be the 'early days'. His work, particularly in transition-metal NMR, critically hinged on technical advances in spectrometer design, and he continuously managed to equip his laboratory with instruments that represented the latest progress in instrumentation. The Institute of Organic Chemistry still has a number of the early instruments with electromagnets on display on its ground floor. Many of the first ${ }^{13} \mathrm{C}$-NMR measurements were performed on a VARIAN XL100-12 spectrometer equipped with an oldfashioned oscilloscope and a punch tape on a teletype terminal. This instrument was very well maintained by our senior assistant Roger Hollenstein and the electronics engineer Kurt Hochreutener so that we could measure all kinds of carbon spectra while saving time for advanced measurements on the high-field instruments.

In anticipation of future needs, i.e. sensitivity enhancement for low-frequency nuclei, Prof. von Philipsborn initiated the development of a very large $20 \mathrm{~mm}$ broadband probe head, which could hold large quantities of substance.

In later times, some of us had the privilege to use the at that time brand-new 600 $\mathrm{MHz}$ instrument, that was soon upgraded to a true three-channel instrument. This allowed easy and exclusively softwarecontrolled channel-switching. In contrast, switching from direct observation into the so-called indirect mode on the contemporary, but somewhat older AM-400 console, required the manual exchange of two boards and connector-replugging, although this instrument was also continuously upgraded. Prof. von Philipsborn was always concerned that the expensive equipment was well-used, including nighttimes and weekends. Saturday mornings were particularly prone to see Phibo on a control mission. The normally very busy schedule needed an accurate reservation system that caused vivid discussions during our weekly Friday morning instrument-time distribution session. However, the agreed plan could be overruled anytime by the golden button of the boss for high priority measurements.

The continuous striving for application of the latest technological developments had an impact on other activities of the group as well. For instance, the first PhD thesis written on a PC originated from $\mathrm{Ph}$ ibo's research group. Unfortunately, there was no compatible printer available on the whole campus of the University of Zurich. The thesis had to be printed at the IBM Research Center in Rüschlikon.

\section{... and Alternative Uses}

Needless to say that the advanced equipment offered a variety of interesting opportunities. Using the XL-200-12's oscilloscope we could play our first computer game called 'dug hunting'. Inadvertently, we also made first attempts at 'zero-field NMR', when one of our postdocs, without realizing that the electromagnet was switched off, tenaciously but in vain tried to acquire a spectrum.

Later, innovative members of the group found another use for the unique $20 \mathrm{~mm}$ probe head in the area of food-related research. By applying 20 watt $\mathrm{CW}$-decoupling power, high-performance water 
cooking of a medium size 'Wienerli' was achieved. The 'Wienerli' was later proudly served to von Philipsborn on the occasion of one of our social events.

Over time and hours of hard work and frustrating endeavors, the $400 \mathrm{MHz}$ spectrometer acquired a peculiar shape of the front plate under the operator desk, which was rumored to result from violent footkick eruptions of certain service assistants (names are known to the authors but will not be disclosed). Users of modern NMR instruments know that nowadays operators are wisely seated at tables that allow full freedom for their legs, but few are likely aware of the reasons for this technological 'breakthrough'.

During times of direct detection of metal or rare nuclei such as ${ }^{15} \mathrm{~N}$ a scanner could easily spend a whole weekend with the acquisition of a single spectrum. In contrast, such long measurement times were increasingly difficult to justify in later times with higher field-strengths and the increased detection sensitivity offered by methods with a two-fold coherence transfer for an indirect detection of insensitive nuclei. Therefore, for the rare case of a weekend emergency a program called 'bluff.exe' existed on the spectrometers, written by one expert within the group, whose name will again not be disclosed...

\section{Relationship of Synthetic Chemists and Spectroscopists}

The group of von Philipsborn comprised graduate students primarily working in either the field of spectroscopy or students that were more focused on synthetic aspects of organometallic chemistry. Both groups usually maintained a friendly relationship. Nevertheless, a critical observer would have noticed different attitudes to science and more general aspects of life. In particular theoreticians in the view of wet-lab chemists were mostly busy turning knobs (for tedious shimming, remember those days were long before the introduction of field-gradient based automatic shimming procedures) and starring at lock levels for prolonged periods of time without any noticeable emotions. A difficult laboratory procedure for them was considered to fill compounds dissolved in a deuterated solvent into NMR tubes (possibly even under protecting argon, a masterpiece in sophistication!). Amongst the spectroscopists a vivid discussion about the smell of synthetic chemists and whether they belong to the species of homo sapiens (are there any recognizable signs of intelligence?) occurred. Needless to say Phibo never interfered with these philosophical discussions.

\section{Synthetic Work in the Group}

Although working on different research topics in NMR, the group members had one thing in common: they were working on scarce, ${ }^{[15]}$ highly sensitive and sometimes very toxic compounds. Many of these compounds had to be prepared by the members of the group themselves or, preferably, at least for some of us, by our collaborating partners from other institutes such as from the Institute of Inorganic Chemistry. In order to keep the availability of the instrumentation at acceptable levels for all members of the group, some of the metal complexes had to be prepared in rather large quantities of up to 15 grams (remember that ${ }^{57} \mathrm{Fe}$ relaxation time are in the range of minutes).

Some of the most toxic compounds (metal-carbonyls, nitrosamines, etc....) were stored in a specifically marked deep freezer. One day we noticed that a delicious fish collection for a dinner party from one of our far-east researchers was kept in this freezer. In order to convince him that he had created toxic waste we needed the persuasive power of strong words from Prof. von Philipsborn.

\section{Exploring the Limits of Transition-metal NMR}

Phibo's group not only crossed the borders of disciplines in science, but also expanded the application range of the laboratory's technologies to the extremes. Due to the low receptivity of ${ }^{57} \mathrm{Fe}$ (4\%o compared to ${ }^{13} \mathrm{C}$ ) special measurements like $\mathrm{T}_{1}$-relaxation time measurements ${ }^{[10]}$ often occupied the most technically advanced instrument for several days. On the other hand, those of us who were interested in sensitive spin $\geq 1$ nuclei, for instance cobalt-59, often finished an experiment within a few seconds (see Fig. 1 and 2).

Not only were extremes in time explored but also extremes in temperature. While most of our group during the early eighties was comfortable with room temperature, a few of us were investigating the dynamics of molecules in the liquid phase at $-100{ }^{\circ} \mathrm{C}$ and below. In pushing the limits, the group was able, for the first time ever, to completely freeze out the rotation of methyl groups into individual NMR signals, one of them at around $-14 \mathrm{ppm}$ relative to TMS. As we were used to look at extreme chemical shift ranges, which in the case of transition-metal NMR can easily cover several thousands of ppm, it was quite common for us to search for resonance peaks in unusual frequency ranges and hence it was no surprise for us to find protons in this region. Today, this type of proton is called 'agostic' and is crucial in understanding metal-induced polymerization.

\section{Methods Developments in Transition-Metal NMR}

Some methodological work dealt with application, development, and theoretical description of experiments with a two-fold coherence transfer for an indirect detection of metal and other insensitive heteronuclei. A particular focus was on systems where a sensitive nucleus is coupled to more than one insensitive nucleus (in general terms: $\mathrm{I}_{\mathrm{n}} \mathrm{S}_{\mathrm{m}}$ spin systems). For example traditional sequences, originally developed for protein and peptide characterization, do not allow detection of rhodium-filtered phosphorus signals in a compound with phosphorus ligands that symmetrically bridge two equivalent rhodium nuclei. However, a simple modification of the pulse sequence allows for indirect metal detection. ${ }^{[16]}$ First spectra of this type, involving both spin- $1 / 2$ as well as spin-1 heteronuclei, were recorded and theoretically described by our group. Indirect detection of spin-1 nuclei was used to characterize the isotopomers of partially deuterated polyhydrido complexes with classical $\mathrm{H}$ - and non-classical

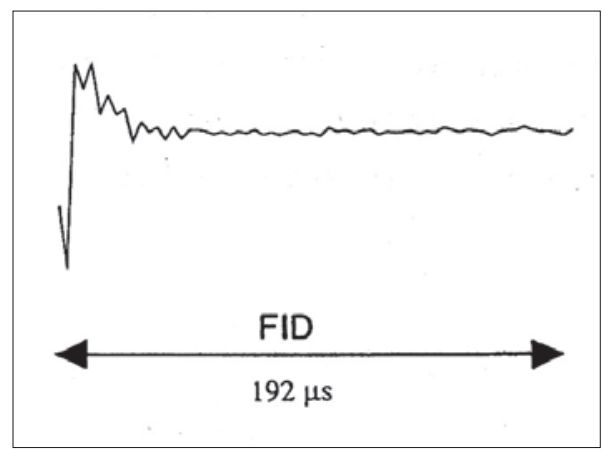

Fig. 1. Ultra-short FID, characteristic of ${ }^{59} \mathrm{Co}$ NMR ...

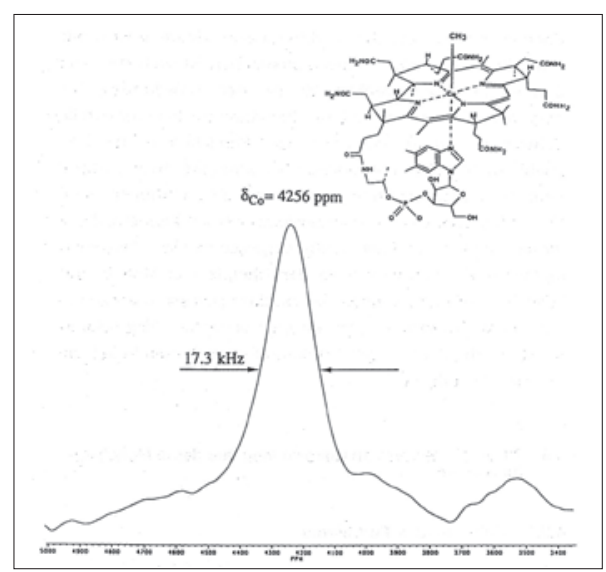

Fig. 2. ... and resulting large line-width of spectra for e.g. methylcobalamine. 
$\mathrm{H}_{2}$ ligands in fast dynamic exchange (see Fig. 3 ). [17]

Heteronuclear double- and singlequantum filters combined with indirect detection methods proved to be the method of choice for the unambiguous determination of the number of hydride ligands in such complexes, ${ }^{[18]}$ and were also applied for characterization of systems with industrial relevance in catalysis. ${ }^{[12]}$

\section{Measurement of Coupling Constants to Quadrupolar Nuclei}

In the early nineties (this was long after the period where stainless-steel devices developed to roast chestnuts were designed in the university's machine shop and declared as NMR sample holders on the invoice) the contact of Wolfgang von Philipsborn to V.N. Torocheshnikov of the Moscow state university initiated a series of publications reporting scalar coupling constants between spin- $1 / 2$ and quadrupolar nuclei. The $\mathbf{J}$ values were determined via iterative line shape analysis of carbon or phosphorus resonances of corresponding ligands attached to manganese. A fit of their quadrupolar broadened line shape by means of the program QUADR, originally developed at Moscow for interactions with spin-1 nuclei, ${ }^{[19]}$ allowed extraction of the mutual J-coupling. The line shapes depend on the scalar coupling constant $\mathrm{J}_{\text {IS }}$, the relaxation time $\mathrm{T}_{1}(\mathrm{~S})$ of the J-coupled quadrupolar nucleus and on a non-quadrupolar contribution $\Delta \mathrm{v}_{\mathrm{NQ}}$ (I) and, in most cases, due to this broadening, J splittings are not resolved in the solution NMR spectra. The fitting procedure was extended to $\mathrm{I}>1$ and applied to the classes of compounds shown in Fig. 4. ${ }^{[4,20,21]}$ The largest ${ }^{1} \mathrm{~J}\left({ }^{55} \mathrm{Mn},{ }^{13} \mathrm{CO}\right)$ values were observed for the tricarbonylcyclopentadienylmanganese complexes (IV). In the series of pentacarbonylmanganese complexes (I) the single-bond $\mathrm{Mn}$ $\mathrm{CO}$ couplings of the axial carbonyls $\left(\mathrm{CO}_{\mathrm{a}}\right)$ are considerably larger than those of corresponding equatorial carbonyls $\left(\mathrm{CO}_{\mathrm{b}}\right)$. This was rationalized by the somewhat shortened $\mathrm{Mn}-\mathrm{CO}_{\text {a }}$ bond lengths for this class of compounds. The influence of the $\mathrm{Mn}-\mathrm{C}$ bond order is directly reflected in the magnitudes of ${ }^{1} \mathrm{~J}\left({ }^{55} \mathrm{Mn},{ }^{13} \mathrm{C}\right)$, with the lowest values $(35-64 \mathrm{~Hz}$ ) for $\mathrm{Mn}-\mathrm{C}$ single bonds (I and II), 97-131 Hz for Mn-carbene complexes and with the largest coupling constants of $168-185 \mathrm{~Hz}$ for the formal triple bond in the case of carbynes (IV). For the tetracarbonylmanganacyle complexes (III) a steady substituent dependence of ${ }^{1} \mathrm{~J}\left({ }^{55} \mathrm{Mn},{ }^{13} \mathrm{CO}_{\mathrm{a}}\right)$ was observed, apparently an interaction with the seven bonds distant ligands attached to the phenyl ring.

The method was applied to pentacarbonylglycosylmanganese complexes to gain

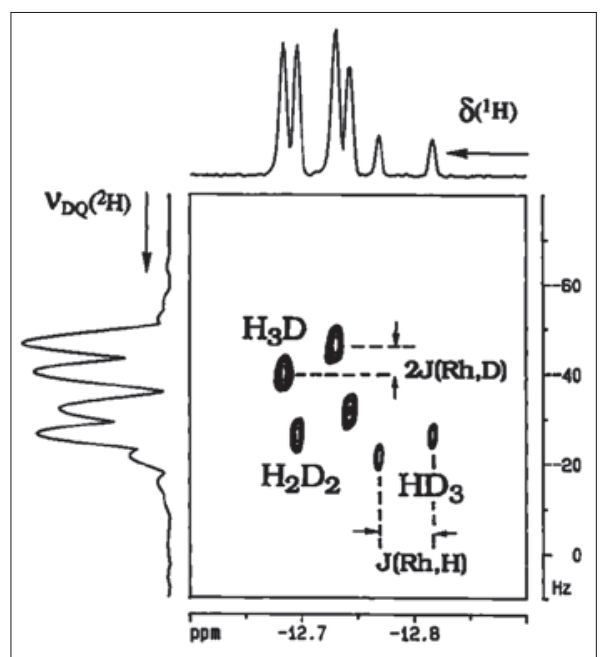

Fig. 3. Correlation of ${ }^{1} \mathrm{H}$ single-quantum and ${ }^{2} \mathrm{H}$-double-quantum resonances of a partially deuterated tetra-hydrido rhodium-complex with two terminal $\mathrm{H}$ - and a non-classical $\mathrm{H}_{2}$ hydrido-ligands in fast dynamic exchange. The spectrum allows straightforward extraction of the ${ }^{1} \mathrm{H}$ and ${ }^{2} \mathrm{H}$ isotope shifts, as well as the ${ }^{1} \mathrm{H}$, ${ }^{103} \mathrm{Rh}$ and ${ }^{2} \mathrm{H},{ }^{103} \mathrm{Rh} \mathrm{J}$-coupling constants of the three only partially deuterated isotopomers.

insight into various migratory insertion reactions resulting in formation of C-glycosyl derivatives. ${ }^{[5]}$ The reliability of the line shape fitting method was established by comparison of the data with results from solid-state ${ }^{13} \mathrm{C}$ or ${ }^{31} \mathrm{P}$ magic angle spinning NMR spectra that exhibited first-order splittings due to the scalar coupling with ${ }^{55} \mathrm{Mn}^{[22]}$ and with the aid of test compounds like $\mathrm{Li}\left[\mathrm{AsF}_{6}\right]$ or $\mathrm{K}_{3}\left[\mathrm{Co}(\mathrm{CN})_{6}\right]$ which allowed direct observation of the J-splitting of resonances in solution. ${ }^{[21]}$

\section{Branching into BioNMR}

Graduate students of the von Philipsborn group were recruited from many places. One of them (O.Z.) had performed his diploma thesis in the field of catalysis using nickel-based organometallic systems. When he joined the group his primary intent was to apply sophisticated 3D NMR techniques (though he did not understand at that time what 3D NMR really meant) to organometallic systems. However, he soon discovered that spectroscopists preferably applied these techniques to proteins for a good reason: Their spectra were sufficiently complex to justify such sophisticated methods, their scalar couplings were sufficiently uniform to tailor pulse sequences for consistently efficient magnetization transfer, and their chemical-shift dispersions were sufficiently large for an assignment of all resonances, in contrast, e.g. to oligosaccharides, to which the first $3 \mathrm{D}$ experiments were applied in the group of Prof. Ernst in Zurich. The first 3D transform on a comparably small data set required more than six hours on the X-32 computer system in the early nineties!

Prof. von Philipsborn was contacted by John Robinson from our institute and by Milan Vašák from the Department of Biochemistry, who both aimed at observing only a selected subset of resonances from the molecules they were working with, by incorporation of isotope markers into the molecular skeleton and the use of NMR isotope-editing or -filtering techniques. John Robinson's project comprised the specific incorporation of ${ }^{13} \mathrm{C}$ and ${ }^{15} \mathrm{~N}$ markers into bradykinin analogues through chemical synthesis followed by isotope-edited l)

$\mathrm{R}: \mathrm{H}$, alkyl, acyl, halogen

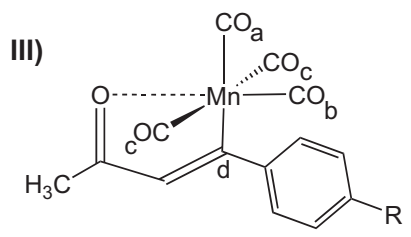

R: OMe, Me, $\mathrm{H}, \mathrm{Cl}, \mathrm{NO}_{2}$

${ }^{1} \mathrm{~J}\left({ }^{55} \mathrm{Mn},{ }^{13} \mathrm{CO}_{\mathrm{a}}\right)=145-174 \mathrm{~Hz}$ ${ }^{1} \mathrm{~J}\left({ }^{55} \mathrm{Mn},{ }^{13} \mathrm{CO}_{\mathrm{b}, \mathrm{c}}\right)=128-143 \mathrm{~Hz}$ ${ }^{1} \mathrm{~J}\left({ }^{55} \mathrm{Mn},{ }^{13} \mathrm{CO}_{\mathrm{e}}\right)=185-220 \mathrm{~Hz}$

${ }^{1} \mathrm{~J}\left({ }^{55} \mathrm{Mn},{ }^{13} \mathrm{C}\left(\mathrm{sp}^{2}\right)\right)=65-81 \mathrm{~Hz}$

${ }^{1} \mathrm{~J}\left({ }^{55} \mathrm{Mn},{ }^{13} \mathrm{C}\left(\mathrm{sp}^{3}\right)\right)=35-64 \mathrm{~Hz}$
II)

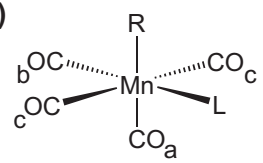

R: alkyl, acyl, halogen

$\mathrm{L}$ : phosphine, amine, isocyanide

IV)

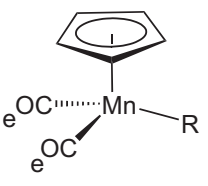

$\mathrm{R}$ : CO, carbene or carbyne ligand

${ }^{1} \mathrm{~J}\left({ }^{55} \mathrm{Mn},{ }^{13} \mathrm{C}\right.$ (carbene $\left.)\right)=97-131 \mathrm{~Hz}$ ${ }^{1} \mathrm{~J}\left({ }^{55} \mathrm{Mn},{ }^{13} \mathrm{C}\right.$ (carbyne $\left.)\right)=168-185 \mathrm{~Hz}$ ${ }^{1} \mathrm{~J}\left({ }^{55} \mathrm{Mn},{ }^{31} \mathrm{P}\right) \quad=191-226 \mathrm{~Hz}$

Fig. 4. Structures of carbonylmanganese complexes I-IV and their scalar coupling constants 


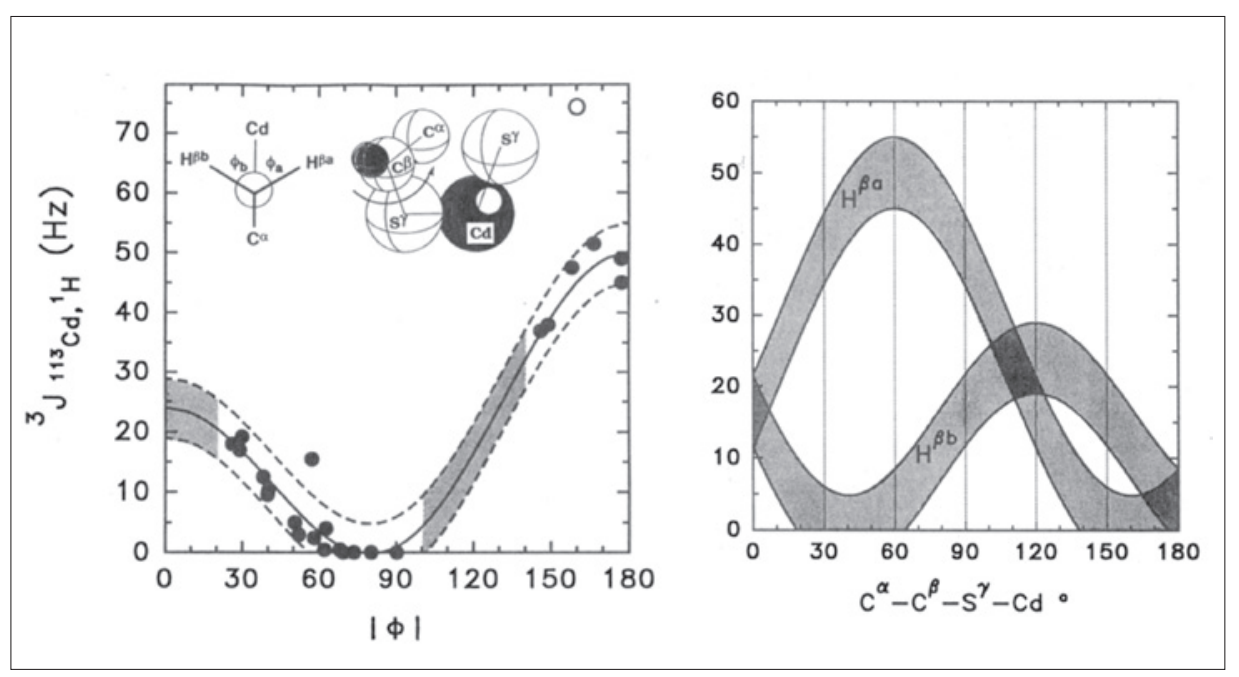

Fig. 5. Left: ${ }^{3} \mathrm{~J}\left({ }^{113} \mathrm{Cd}, \mathrm{H} \beta\right)$ couplings vs. the angle $\phi$ (see text); Right: pairs of corresponding ${ }^{3} \mathrm{~J}$ couplings of the methylene protons

ROESY spectroscopic analysis. ${ }^{[23]}$ The system was ideally suited to test our new triple-resonance probe and hardware, and the experiments proved that by replacing certain proline residues in bradykinin by $\alpha$-methyl proline stabilized a beta-turn ${ }^{[24]}$ conformation of the peptide. To support biosynthetic studies of John Robinson also deuterium and tritium NMR was applied. Milan Vašák from the Department of Biochemistry was interested in using ${ }^{113} \mathrm{Cd},{ }^{1} \mathrm{H}$ scalar couplings in metallothioneins to extract information about the dihedral angle around the sulfur-C(beta) bond.[25] Measurements of such couplings in Desulfofibrio gigas rubredoxin and in rat-liver metallothionein revealed a Karplus-type relationship of the ${ }^{3} \mathrm{~J}\left({ }^{113} \mathrm{Cd}, \mathrm{H} \beta\right)$ coupling on the dihedral angle (see Fig. 5).

\section{Concluding Remarks}

While writing up this personal account on our experiences in the group of von Philipsborn we realized that period was a very fruitful time in our lives, both from a personal and from a scientific point of view. Even 25 years later we still are very good friends, and we share remembrances of many special moments. Members of the von Philipsborn group can nowadays be found in academia and industry, in chemistry and widely different kinds of jobs. We would all like to thank our mentor for the honor of being part of his group for an important part of our life, for forming many long-lasting friendships, and for developing an attitude of approaching other people in a way that is based on respect, generosity, listening and mutual understanding. We wish Phibo all the best for the coming years!
[1] C. M. Adams, A. Hafner, M. Koller, A. Marcuzzi, R. Prewo, I. Solana, B. Vincent, W. von Philipsborn, Helv. Chim. Acta 1989, 72 , 1658.

[2] H. Bönnemann, W. Brijoux, R. Brinkmann, W. Meurers, R. Mynott, W. von Philipsborn, T. J. Egolf, Organomet. Chem. 1984, 272, 231.

[3] P. DeShong, D. R. Sidler, P. J. Rybczynski, A. A. Ogilvie, W. von Philipsborn, J. Org. Chem. 1989, 54, 5432; P. DeShong, G. A. Slough, D. R. Sidler, P. J. Rybczynski, W. von Philipsborn, R. W. Kunz, B. E. Bursten, T. W. Clayton, Organometallics 1989, 8, 1381.

[4] D. Rentsch, L. Nill, W. von Philipsborn, D. R. Sidler, P. J. Rybczynski, P. DeShong, Magn. Reson. Chem. 1998, 36, S54.

[5] P.DeShong,E.D. Soli, G. A. Slough, D. R. Sidler, V. Elango, P. J. Rybczynski, L. J. S. Vosejpka, T. A. Lessen, T. X. Le, G. B. Anderson, G. B.; W. von Philipsborn, M. Vöhler, D. Rentsch, O. Zerbe, J. Organomet. Chem. 2000, 593, 49.

[6] W. von Philipsborn, R. Müller, Angew. Chem. Int. Ed. 1986, 25, 383

[7] W. von Philipsborn, Pure Appl. Chem. 1986, 58, 513; W. von Philipsborn, Chem. Soc. Rev. 1999, $28,95$.

[8] M. Bühl, G. Hopp, W. von Philipsborn, S. Beck, M. H. Prosenc, U. Rief, H. H. Brintzinger, Organometallics 1996, 15, 778; T. Jenny, W. von Philipsborn, J. Kronenbitter, A. Schwenk, J. Organomet. Chem. 1981, 205, 211; E. J. M. Meier,W. Kozminski,A.Linden, P.Lustenberger, W. von Philipsborn, Organometallics 1996, 15 , 2469.

[9] M. Koller, W. von Philipsborn, Organometallics 1992, 11,467

[10] A. Hafner, W. von Philipsborn, A. Schwenk, $J$. Magn. Reson. 1987, 74, 433.

[11] V.Tedesco, W. von Philipsborn, Organometallics 1995, 14, 3600.

[12] B. R. Bender, M. Koller, D. Nanz, W. von Philipsborn, J. Am. Chem. Soc. 1993, 115, 5889.

[13] K. V. Schenker, W. von Philipsborn, J. Magn. Reson. 1985, 61, 294; K. V. Schenker, W. von Philipsborn, J. Magn. Reson. 1986, 66, 219; W. Kozminski, W. von Philipsborn, J. Magn. Reson. Ser. A 1995, 116, 262.

[14] H. Egli, W. von Philipsborn, Org. Magn. Reson. 1981, 15, 404; H. Egli, W. von Philipsborn, Helv. Chim. Acta 1981, 64, 976.

[15] P. B. Graham, M. D. Rausch, K. Täschler, W. von Philipsborn, Organometallics 1991, 9, 3049.

[16] D. Nanz, W. von Philipsborn, J. Magn. Reson. $1991,92,560$.
[17] D. Nanz, W. von Philipsborn, J. Magn. Reson. 1992, 100, 243

[18] U. E. Bucher, T. Lengweiler, D. Nanz, W. von Philipsborn, L. M. Venanzi, Angew. Chem., Int. Ed. 1990, 29, 548.

[19] I. F. Leshcheva, V. N. Torocheshnikov, N. M. Sergeyev, V. A. Chertkov, V. N. Khlopkov, J. Magn. Reson. 1991, 94, 1.

[20] V. Torocheshnikov, D. Rentsch, W. von Philipsborn, Magn. Reson. Chem. 1994, 32, 348.

[21] D. Rentsch, W. von Philipsborn, V. Torocheshnikov, Magn. Reson. Chem. 1996, 34, 955.

[22] D. Rentsch, R. Hany, W. von Philipsborn, Magn. Reson. Chem. 1997, 35, 832.

[23] O. Zerbe, J. H. Welsh, J. A. Robinson, W. von Philipsborn, J. Magn. Reson. 1992, 100, 329.

[24] J. H. Welsh, O. Zerbe, W. von Philipsborn, J. A. Robinson, Febs. Lett. 1992, 297, 216.

[25] C. J. Henehan, D. L. Pountney, O. Zerbe, M. Vašák, Protein Sci. 1993, 2, 1756; O. Zerbe, D. L. Pountney, M. Vašák, J. Am. Chem. Soc. 1994 116, 377; D. L. Pountney, O. Zerbe, W. von Philipsborn, J. B. Egan, M. Vašák, Bull. Magn. Reson. 1995, 17, 145. 